\title{
ANTIQUITY
}

system will doubtless need modification, but it is hoped that a detailed study of the 56,000 coins from Richborough now in progress will suggest a final form of periods and subdivisions and so present a sound basis for national and international comparisons.

PETER CURNOW and RICHARD REECE

[I] R. E. M. and T. V. Wheeler, Verulamium (1936), 42, pl. cxviii.

[2] ANTIQUITY, I964, 104 and fig. 2.

[3] S. S. Frere, Britannia (1967), 253.

[4] St Albans and Herts. Arch. and Arch. Soc. Trans., I $935,243$.

[5] ANTIQUITY, I964, I1 I.

\section{Tree-felling by Fire}

The following note has been sent to us by Thurstan Shaw, Research Professor of Archaeology in the Institute of African Studies, University of Ibadan, Nigeria.

The part that fire has played as an instrument in the clearance of forested areas for purposes of early agriculture has long been recognized, but doubt has sometimes been expressed about its capacity to deal with large forest trees. Readers of ANTIQUITY may therefore be interested in a photograph which shows a large tree in the rain forest of West Africa being felled by fire (PL. via). The tree had previously been killed by
[6] e.g. P-M. Favret, Note sur un vase zoomorphique (I909); J. Déchelette, Manuel d'Archéologie (1914), Vol. III, 3, 1467, and fig. 662 .

[7] For a drawing of this brooch see Antiq. Fourn., XLvil, 1967, 290; Mr M. R. Hull has drawn my attention to an extremely close parallel from the Magdalensberg, Austria: Carinthia I, 142, 1942, I 54 and fig. I.

[8] cf. Archaeologia., CI, I967, 38, and fig. 23.

[9] Antiq. Fourn., XLI, 1961, 44 .

[10] Germania, xxxix, 196I, 196.

[II] See [I], 4I.

[12] Antiq. Fourn., xxxvir, r957, 6; ibid., xxxvil, 1958, 13; ibid., XII, 1961, 75, n. 6.

[I3] $\mathcal{F R S , ~ L I V , ~ I 9 6 4 , ~} 166$.

[14] Antiq. Fourn., XI.I, I961, 75, and fig. 2.

[I 5] ANTIQUITY, 1964, ro3.

PLATE VI $a$

the removal of the bark from the lower part of the trunk, but a man attempting to fell it with a modern steel axe made very little impression upon it after a whole day's work. Accordingly a fire was set around the base of the trunk, and was kept burning continuously for 60 hours, at the end of which period, as a result of the regulation of the fire, the tree fell in precisely the desired spot. I measured the tree after its fall as having been $44 \mathrm{~m}$. high. I estimated the total expenditure of labour, consisting of barkstripping, collecting firewood and tending the fire, as 6 hours.

\section{South Cadbury Excavations, I968}

In 1968 , six sites were excavated, four in the interior, one across the inner rampart, and one at the south-west gate. The great variety of structures and objects recovered is best dealt with by concentrating on the highlights of each period.

For the Early Neolithic, the greatest surprise was the discovery of a vigorous culture beneath the first Iron Age rampart. There, sealed by the old land surface, were pits rich in flint flakes and pottery; a scatter of charcoal; and a suggestion of a bank of roughly piled stones. In the rampart cutting on the south side of the hill, this Neolithic bank stood at the point where the relatively gentle slope of the Cadbury hilltop plunges steeply to the valley-the most effective line, that is, for defensive purposes, and the one chosen therefore by the Iron Age defenders. This siting looks so deliberate that one is tempted to predict that a similar Neolithic bank may be found in a comparable position all round the hill; and if this is so, then Neolithic Cadbury would have been an embanked settlement of about 20 acres (c. 8 hectares). A provisional date for the settlement is provided by the thermoluminescence technique. Measurements at the Oxford Research Laboratory for Archaeology give the following dates for two Neolithic sherds recovered in 1967: $3300 \pm$ $800 \mathrm{BC}$ and $335^{\circ} \pm 800 \mathrm{BC}$.

Thereafter the hilltop was abandoned for two millennia or longer, until early in the Ist 

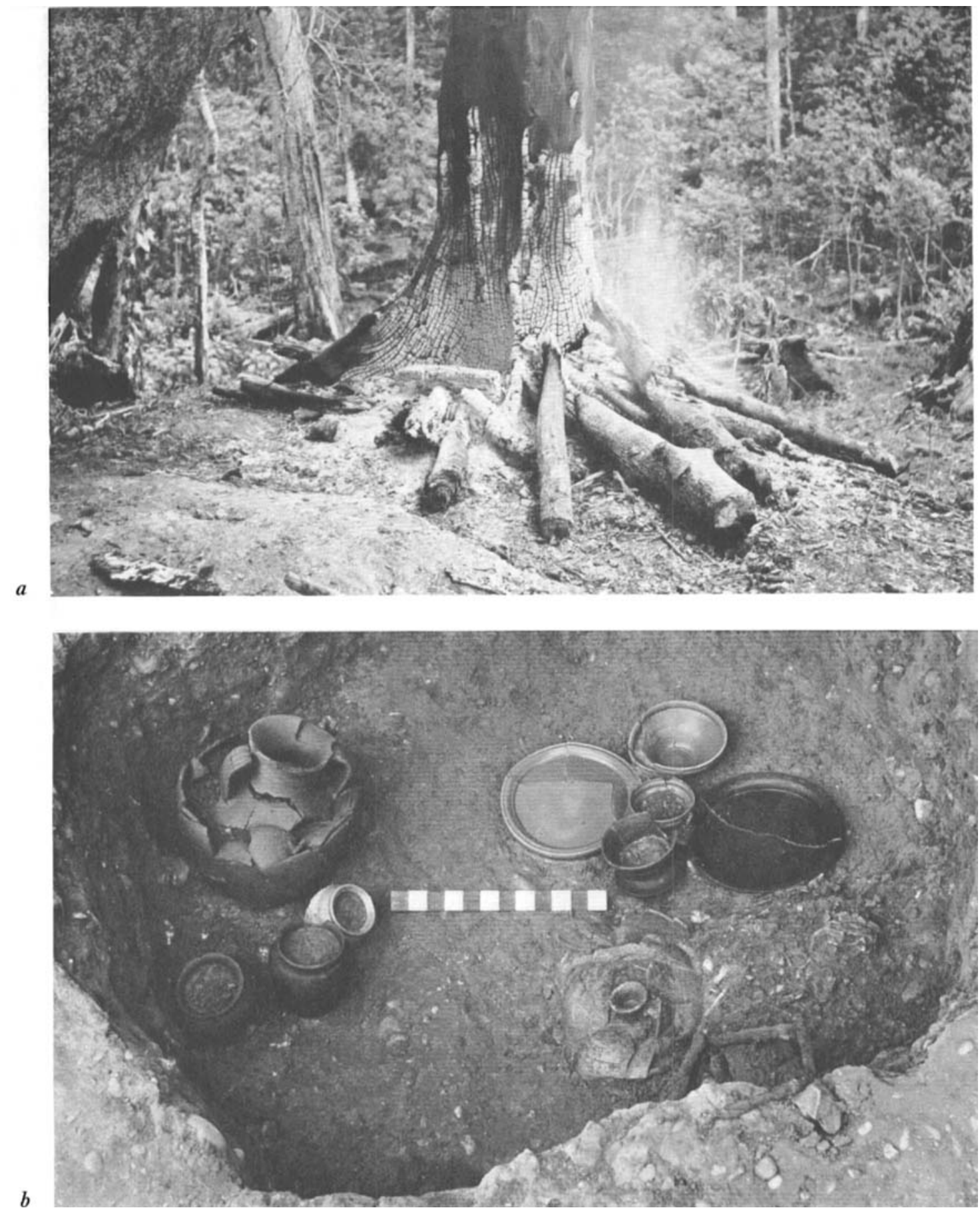

(a) TREE-FELLING BY FIRE. This tree, $44 \mathrm{~m}$. high, was felled by fire in 60 hours. (b) VERU I.AMIU M, I966-8. La Tène III grave group, King Harry Lane cemetery

See pp. 52 and 45-52]

[Photos: (a) Thurstan Shaw (b) A. L. Pacitto 


\section{NOTES AND NEWS}

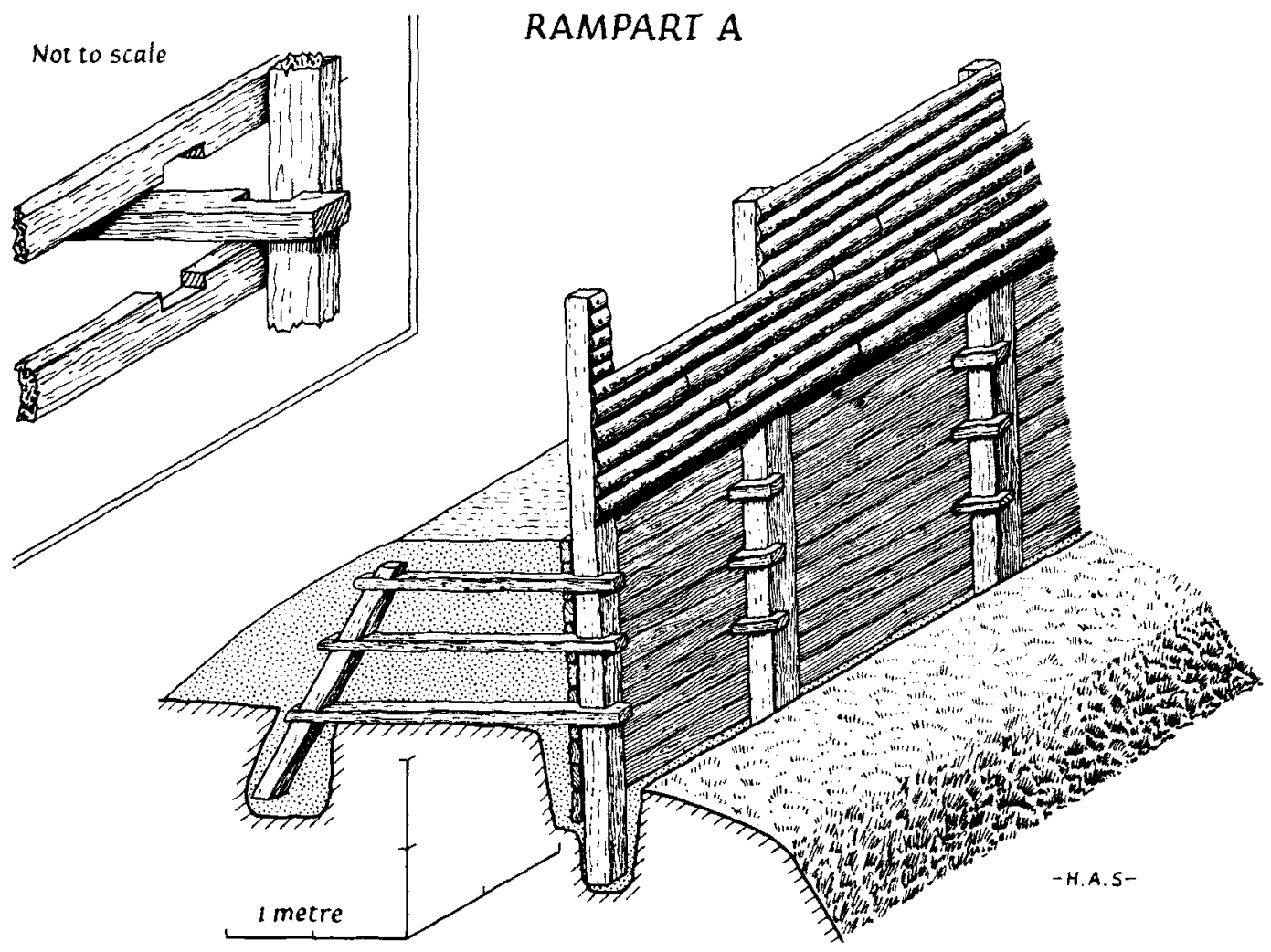

Fig. I. Rampart A. Oblique projection

millennium BC. In 1967 , fairly abundant evidence of occupation in the Late Bronze Age and Initial (Scarborough-Staple Howe) PreRoman Iron Age was recovered from the top of the hill. This season, the rarity of comparable material from beneath the inner rampart, from its make-up, or from occupation levels behind it suggests very strongly that in the first half of the Ist millennium there was nothing more than a farmstead or hamlet on the hill. On the evidence examined so far, the building of the defences goes back no earlier than an Early (Hengistbury A) PRIA phase. Between then and the Roman sack and slighting about $A D 45$, the inner rampart was rebuilt at least three times, while the three outer banks were added and remodelled in the later phases of this sequence.

The earliest phase of the inner bank, Rampart A (FIG. I), was a structure of clay and small stones derived from the weathered upper levels of the bed-rock and held in a timber frame. At the front of the decayed Neolithic bank, the hill-slope was cut back to an almost vertical face to provide seating for the lowest timber in a revetment of horizontal planks. In front of this, post-pits were dug at intervals ranging from $\mathrm{I} \cdot 05 \mathrm{~m}$. to $\mathrm{I} \cdot 40 \mathrm{~m}$. to hold upright posts of $0.15 \mathrm{~m}$. scantling. About $\mathrm{x} .60 \mathrm{~m}$. behind this front revetment was a rear row of posts, some of them vertical, others leaning slightly forwards. A square, shallow groove running forwards from one of these rear posts was the only indication of transverse ties; but it seems reasonable to suggest that other ties had originally existed, and that as they decayed the small loose stones of the bank had settled, obliterating all trace of timberwork.

In the reconstruction, it is assumed that all 


\section{ANTIQUITY}

timbers, except those for the breastwork, were roughly squared with adzes. Since the known transverse timber ran straight from its corresponding rear post, it is reasonable to believe that rear posts and transverse ties were halved together. But it is unlikely that the front uprights and the ties were similarly jointed, because this would have weakened the main loadbearing posts. It is suggested therefore that the ties, having passed through the planks of the revetment, were notched around the front uprights, which were thus kept intact. No sophisticated knowledge of jointing or carpentry technique is implied here. Nonetheless, people whose continental ancestors built carts and plank burial chambers are likely to have been fairly skilled carpenters. We should also notice the great quantity of timber involved. Assuming, as in FIG. I, a revetment $\mathrm{r} \cdot 50 \mathrm{~m}$. high, with 12 planks in that height, then some 14,000 to $15,000 \mathrm{~m}$. of planking would have been needed for the revetment alone, not counting the uprights, ties or breastwork. The cutting and dressing of this timber implies both enormous human effort and also large-scale deforestation.

Rampart A had largely collapsed, and a soil had formed over it before Rampart B was built (FIG. 2). The major differences between this and Rampart A were threefold. While there were similar uprights at the front supporting a breastwork, there was now no planking behind the uprights, but instead a stone revetment between them. Next, because the ditch had now penetrated to more solid bed-rock, the main body of the rampart consisted of massive blocks and slabs of Inferior Oolite, roughly laid, but with no transverse ties. Finally, instead of a rear row of upright or sloping posts halved to transverse ties, there was a row of fairly closeset posts which presumably held a revetment of planks supporting the back of the rampart.

Several of these features deserve further consideration. The stone revetment consisted of thin lias limestone slabs, specially imported to the hill from several miles away. Presumably lias was used because its ready fracture into very even slabs was thought to make it especially suitable for a revetment. It had however the defect of its virtue, for it seems that it continued to split into thinner slabs and smaller blocks. Moreover it does not seem to have been bonded back into the core of Oolite blocks. It therefore formed a mere skin, very ready to slide and collapse. Indeed, the lower courses were well preserved simply because the upper part of the revetment had slid forward over them. Meanwhile the massive blocks of the rampart core had remained stable. There is no sign that any settlement had taken place in the core, and it is this which makes it possible to say that there had been no transverse ties in Rampart B. This in turn implies that South Cadbury is not a true example of a 'Preist' type rampart. Two other features should be noticed: the strength of the timber uprights, posts of $0.15 \mathrm{~m}$. or more scantling, set $1.0 \mathrm{~m}$. deep in the ground; and the rough levelling of the top of the rampart core, apparently as a rampart walk.

Finally, some comment should be made on the superficial resemblance between the reconstruction of Rampart B and that offered for the post-Roman or 'Arthurian' defence discovered in 1967 (ANTIQUITY, 1968, 51), a work which should now be designated Rampart E. The evidence of stratification and associated finds is of course conclusive for the wide difference in date of these two ramparts; and there is also a marked difference in the character of their revetments. However inept we may consider the skin of lias slabs of Rampart B, it was at least neatly built, and the timbers which rose through it securely founded. By contrast, Rampart E had a crudely laid revetment of irregular Oolite blocks; even the ground course tilted forward; and the timbers were not deeply bedded-some of them, indeed, did not even penetrate the contemporary ground surface. Behind the apparent resemblances there is a very wide difference of skill.

No reconstructions can be offered for the later pre-Roman defences, Ramparts $\mathrm{C}$ and $\mathrm{D}$, because in our 1968 trench their fronts had collapsed down the hill and their rear features have still to be disentangled. Rampart D was overlaid by a depth of ploughsoil before the building of Rampart E, which in turn was overlaid by $\mathrm{F}$, the Late Saxon burh bank with a mortared wall in front. New information about 


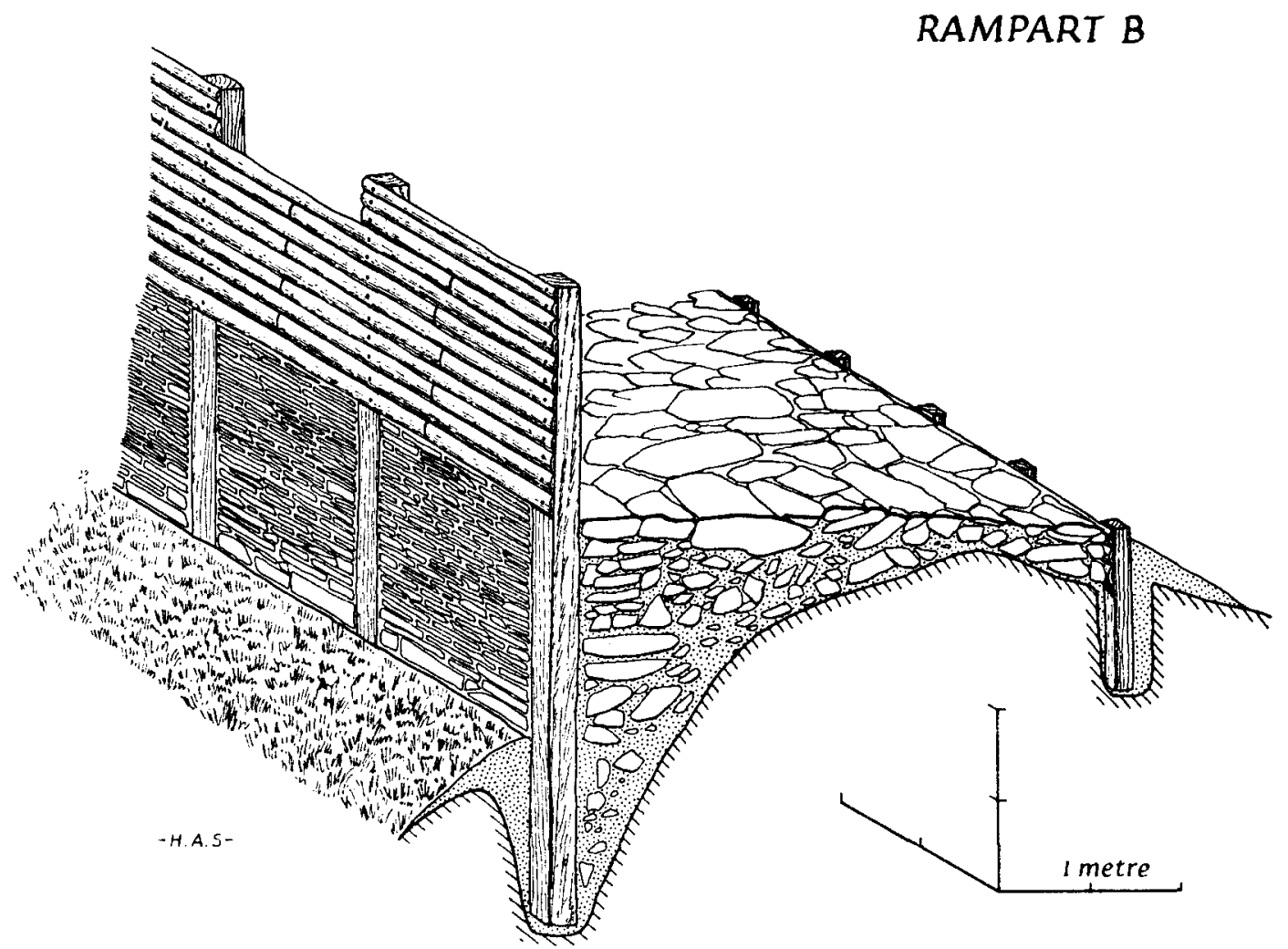

Fig. 2. Rampart B. Oblique projection

this comes from the south-west gate. This had the form of a simple passage-way at least $8.0 \mathrm{~m}$. long by $3.50 \mathrm{~m}$. wide, faced in lias slabs. At the outer end was a single portal, with the responds of an arch carried up in Ham-stone, and the gate itself pivoting on a Ham-stone slab. This Aethelredan gate had been savagely slighted, presumably under Cnut, with no more than three course of stonework left intact. The actual facing stones, both Ham and Lias, were carted away not only from the gate but from the whole perimeter of the burh. After an unknown interval, the gate was refashioned in massive blocks, laid without mortar, and at the same time the inner face of the burh bank was reveted in dry stonework. Much effort but little skill was expanded in this final rebuilding of the gates and perimeter of South Cadbury, but the historical context of the work is at present unknown.
Turning now to the interior, the major problem in 1968 , as in previous seasons, was that of locating significant buildings prior to digging, so that the resources available for excavation could be concentrated in the most rewarding areas. A detailed comparison of site EFG excavated in 1967 with the geophysical indications showed that, given the actual conditions at South Cadbury and given the instruments currently available, buildings with wide foundation trenches or drainage gullies, both circular and rectilinear, could be picked up; but buildings with narrow wall-trenches, and postbuilt structures, would not emerge through the palimpsest on this site, or would not be picked up at all. None of the buildings uncovered this year had been predicted from geophysical surveys.

Buildings of the Pre-Roman Iron Age include one $4.0 \mathrm{~m}$. in diameter with a low wall of 


\section{ANTIQUITY}

stones much damaged by ploughing. A larger round house, about $1 \mathrm{I} \cdot 0 \mathrm{~m}$. in diameter, had a wall of stakes, presumably supporting wickerwork, and an inner ring of large, deep postholes to hold the main roof supports. Another structure probably attributable to the Iron Age was marked by a rectangular setting, $5.0 \mathrm{~m}$. by $4.0 \mathrm{~m}$., of exceptionally large posts, up to $0.40 \mathrm{~m}$. in scantling. This building, virtually on the summit of the hill, and surrounded by pits containing carefully buried horse and ox skulls, suggests a timber shrine.

Evidence has accumulated during previous seasons that the native occupation of the hillfort ended in fire and the sword at the Roman Conquest. It appeared that the surviving inhabitants were removed from the fort, and it was believed that the Romans themselves had made no use of it. This hypothesis must now be abandoned because this season, in an area which had already yielded Roman military equipment, the wall-trenches of a prefabricated rectangular building of timber were found. A hobnail from one of the wall-trenches confirms the suggestion of the plan and constructional technique, that this was a Roman military building.

In another area on the summit ridge, part of a structure belonging to the post-Roman, 'Arthurian', occupation was uncovered. The cutting in question yielded an unusual quantity of imported 6th-century pottery of Tintagel type, most of it scattered in top soil, some of it from a pit, and two sherds from the filling of the wall-trench of one side of a rectangular building. These two sherds were noticeably less weathered than the others from the cutting. Among those too timid to grasp the Arthurian nettle, or too ill-informed about the 6th century $\mathrm{AD}$, much ingenuity has been, and will be, expended to explain these sherds away; but the most natural explanation for their condition and stratification is that they were tamped into the filling of the trench shortly after their parent vessel had been broken. In other words, they date the building. This season only one wall, most probably a gable end, was uncovered. The full exploration of this building must be a major objective in Ig69.

Looking ahead to the coming season, we may say this. Among the many medium to large hillforts of southern Britain, South Cadbury Castle has three unusual features: extensive traces of Early Neolithic settlement; 'Arthurian' defences and buildings; and the Late Saxon burh. About the defences and gates of the latter we now have plentiful information; and short of discovering, most probably by happy chance, the Aethelredan mint we do not expect to learn much more about this period. But in the case of the Neolithic and 'Arthurian' periods, we are at present merely on the brink of important discoveries. Determining the full limits of the Neolithic settlement, and exploring the structure of which one corner was found in 1967 , uncovering the 'Arthurian' building on the summit ridge, and exploring the contemporary gateway: these are four important objectives in themselves, but they are underlaid by the need for greater knowledge of the long, rich and complex later Bronze Age and Iron Age history. Given adequate resources, the final seasons at South Cadbury promise to be unusually rewarding.

LESLIE ALCOCK

\section{A Foundation Sacrifice at Birkenhead Priory}

The following note was sent to us by Mrs Nora $F$. McMillan of the Fane Herdman Laboratories of Geology of the University of Liverpool. It was written some years ago, shortly before $\mathrm{Mr} \mathrm{Fer}$ gusson Irwin's death at the age of 93 .

Birkenhead Priory, a Benedictine monastery founded in 1150 , was presented to Birkenhead Corporation in 1896 when also a careful restoration of the surviving building was made. The work of restoration was carried out by G. W. Haswell of Chester under the supervision of E. W. Cox and a full account was published by A. M. Robinson (1905). Yet the finding of animal bones in a carefully prepared cavity at the foot of one of the buttresses has not been recorded, save ephemerally and incorrectly in a local newspaper (Robinson I898).

The bones in question are preserved in the 